\title{
Evaluation of CD44 and CD133 as markers of liver cancer stem cells in Egyptian patients with HCV- induced chronic liver diseases versus hepatocellular carcinoma
}

Mohammed Saeed Rozeik ${ }^{1}$, Olfat Ali Hammam², Ali Ibrahim Ali $^{1}$, Mona Magdy ${ }^{2}$, Heba Khalil ${ }^{2}$, Amgad Anas ${ }^{3}$, Ahmed Abdelaleem Abo el Hassan ${ }^{1}$, Ali Abdel Rahim ${ }^{3}$, Ahmed Ibrahim El-Shabasy ${ }^{1}$

${ }^{1}$ M.D., Tropical Medicine Department, Faculty of Medicine, Al-Azhar University, Cairo, Egypt

${ }^{2}$ M.D., Pathology Department, Theodor Bilharz Research Institute, Imbaba, Giza, Egypt

${ }^{3}$ M.D., Tropical Medicine Department, Theodor Bilharz Research Institute, Imbaba, Giza, Egypt

Type of article: Original

\begin{abstract}
Background: Cancer stem cells (CSCs) play a critical role in tumor development, progression, metastasis and recurrence.

Aim: To evaluate hepatic expression of CD44 and CD133 in Egyptian patients with HCV-induced chronic liver diseases and hepatocellular carcinomas (HCCs), and to assess its correlation with inflammatory activity scores, stages of fibrosis (in chronic hepatitis with or without cirrhosis) and grades of HCC.

Methods: This prospective case-control study was conducted on eighty subjects who attended the Tropical Diseases Department, Al-Azhar University Hospital, and in collaboration with Theodor Bilharz Research Institute (2014-2016). They were divided as follows: A) Control healthy group: Ten individuals with serologically negative $\mathrm{HCV}-\mathrm{Ab}$ and $\mathrm{HBsAg}$, and histopathologically normal liver, B) Seventy patients subdivided into 3 groups; Twenty subjects each, as: HCV-Ab+ non-cirrhotic, HCV-Ab+ cirrhotic and HCC. Necroinflammatory activity and fibrosis in non-neoplastic liver biopsies were scored according to the METAVIR scoring system. CD44 and CD133 immunostaining was evaluated in all groups semi-quantitatively using H score. Statistical analysis was performed by SPSS version 22, using independent-samples t-test.

Results: Our study showed a significant increase of mean CD44 \& CD133 expression values with disease progression among the groups $(\mathrm{p}<0.05)$. Their expressions increased significantly with the inflammatory activity scores and stages of fibrosis, reaching the highest values in A3F4 score compared to A1F1 $(p<0.05)$. Moreover, there was a significant increase of their expressions across HCC grades $(p<0.05)$, however with no significant correlation with focal lesions size.

Conclusion: CSCs clusters exhibiting CD133+ and/or CD44+ profiles were identified in chronic hepatitis, liver cirrhosis and HCC. CD133 and CD44 expressions significantly corresponded to the increased inflammatory activity, fibrosis stages and higher tumor grades. Therefore, evaluation of CD44 and CD133 expression profiles as CSCs markers in non-neoplastic liver and HCCs can help in development of novel therapeutic agents for HCC targeting and prevention.
\end{abstract}

Keywords: hepatocellular carcinoma, Cancer stem cell, CD133, CD44, METAVIR

\section{Introduction}

Hepatocellular carcinoma (HCC) is the most common liver cancer, the sixth most common cancer worldwide and the third leading cause of cancer-related death (1). It is estimated that each year, half a million new cases are diagnosed worldwide. It was reported that developing countries have the highest prevalence of the disease (2). Although there are extensive regional variations in the causes and spread of HCC, chronic hepatitis B virus (HBV) and HCV infection make up the majority of HCC cases worldwide (3), with Egypt having the highest prevalence of $\mathrm{HCV}$ (4). $\mathrm{HCC}$ - as the main complication of cirrhosis - shows a growing incidence, as HCV is a primary risk factor

\section{Corresponding author:}

Professor Dr. Olfat Hammam, Pathology Department, Theodor Bilharz Research Institute, El-Nile Street, Warrak El-Hadar, Imbaba P.O. Box 30, Giza 12411, Egypt. Tel: +20201001815577, E-mail: totoali1@hotmail.com

Received: May 04, 2017, Accepted: June 11, 2017, Published: July 2017

iThenticate screening: June 11, 2017, English editing: June 27, 2017, Quality control: July 12, 2017

(C) 2017 The Authors. This is an open access article under the terms of the Creative Commons Attribution-NonCommercialNoDerivs License, which permits use and distribution in any medium, provided the original work is properly cited, the use is non-commercial and no modifications or adaptations are made. 
$(5,6)$. Although, during the past few decades, there has been development in its treatment process, the prognosis of HCC still remains poor, largely because of the high recurrence rate which can reach as high as $70 \%$ following conventional methods like chemotherapy, surgical resection, arterial embolization, and radiofrequency ablation (7). Despite the cytological pathogenesis of HCC being unclear, HCCs exhibit great heterogeneity (8). In this regard, there are fewer cancer cells with stem cell properties, called liver cancer stem cells (LCSCs), responsible for HCC growth, metastasis or recurrence, or indeed chemotherapy and radiotherapy failure (9). Thus, although most tumor cells are killed off by liver cancer therapies, the possibility remains that therapies can still fail because of the inability to eliminate LCSCs, which survive to develop new tumors. Therefore, the theory of the cancer stem cell offers a different understanding of tumor diagnosis, treatment and prevention. So, in order to achieve greater knowledge, and consequently, better treatment of liver CSCs, we must recognize their markers of stemness which correspond to poor prognosis, metastasis, and resistance. Markers of stemness are necessary to study CSCs biological characteristics so they can be targeted efficiently for therapeutic purposes (10). In this regard, CD44 is a multifunctional class I transmembrane glycoprotein (11). Typically, it is mostly involved in homing, cell cell, cell matrix interactions, cell migration, production and formation of new blood vessels (angiogenesis) in which, under certain situations, they pathologically characterize malignancy (12). Furthermore, CD44 was recognized as CSCs marker in a number of human cancers, including breast cancer (13), gastric cancer, prostatic cancer (14) and colorectal malignancies (15). Its expression is associated with poor HCC prognosis $(16,17)$. Furthermore, CD44+ LCSCs are associated with metastasis and tumor invasiveness (18). In the same context, since other markers were reported to more accurately define the surface phenotype of LCSCs (19), CD133 (Prominin-1) - a membrane glycoprotein encoded by the CD133/ Prom-1 gene (20) was first detected as a marker of hematopoietic stem cells and then it was reported to be a marker of CSCs in prostatic, colonic, and ovarian tumors (21-23). Furthermore, Suetsugu et al. (24) initially identified CD133+ HCC cells as CSCs subpopulation which display greater proliferative and tumorigenic potential, as well as lower levels of mature hepatocyte marker expressions in comparison to CD133- counterparts, thus considering that CD133+ cells signify loss of differentiation in tumors (25). Moreover, it was suggested that enhanced CD133 expression was an independent prognostic indicator for survival and recurrence of tumors in HCC patients (17). Our study aimed at evaluation of the hepatic expression of CD44 and CD133 in Egyptian patients with HCV-induced chronic liver diseases and HCC, as well as assessment of the correlation of their expression with inflammatory activity scores, stages of fibrosis (in chronic hepatitis with or without cirrhosis) and grades of HCC.

\section{Material and Methods}

\subsection{Research design and participants}

This prospective case-control study was carried out on eighty subjects who attended the Department of Tropical Diseases at Al-Azhar University Hospital, and in collaboration with Theodor Bilharz Research Institute, in the period from October 2014 to March 2016. Control group consisted of ten healthy individuals that histopathologically showed normal liver profile and serologically were negative for HCV-Ab and HBsAg. The other seventy patients were divided into three groups, each composed of twenty subjects, as follows: I) HCV-Ab positive non-cirrhotic group, II) HCV-Ab positive cirrhotic group, III) HCC. All subjects underwent complete history analysis, full physical examination, routine laboratory investigations, abdominal ultrasound and Triphasic Spiral Computed Tomography (CT) for HCC patients.

\subsection{Histological assessment}

Ultrasound guided liver biopsies were performed under local anesthesia using a 16-gauge Tru-cut needle (QuickCore, Cook-Medical, Bloomington, Indiana, USA). Hepatocellular carcinomas were obtained from partial hepatectomy specimens. The liver biopsies were scored according to METAVIR scoring system for necroinflammatory activity and fibrosis grading (26).

\subsection{Specimen Collection and Handling}

Specimens were fixed in $10 \%$ buffered formalin. Paraffin blocks were prepared. Histopathologic sections were cut at $4 \mu \mathrm{m}$ thick. All slides were treated with 3-amino-propyl-triethoxysilane (3APTES/SIGMA-A-3648). These slides were used instead of the ordinary albumenized slides to minimize staining artifacts and for better fixation of sections on the slides.

\subsection{Immunohistochemistry staining for detection of CD44 and CD133 antigens}

Immunohistochemical reaction was performed using avidin biotin complex $(A B C)$ immunoperoxidase technique according to Hsu and Raine (27). Sections were de-waxed in xylene, and hydrated in descending grades of ethanol. 
Endogenous peroxidase activity was quenched by incubation in 3\% hydrogen peroxide and then in $100 \%$ methanol for 20 minutes. Antigen retrieval was performed by microwaving the sections in citrate buffer (PH 6.0) for 15 minutes at $700 \mathrm{~W}$. Sections were incubated overnight at $40 \mathrm{C}$ with the antihuman primary monoclonal antibodies against CD44 and CD133 (Santa Cruz Biotechnology Inc.; Santa Cruz, USA) and diluted at 1:100 and 1:150 respectively. Next day, sections were washed in PBS then incubated with streptavidin-biotin peroxidase complex and substantiated using a peroxidase/DAB (diaminobenzidine) enzymatic reaction for CD44 and CD133. Staining was completed by 5 to 10 minutes incubation with 3, 3'- diaminobenzidine (DAB) + substrate - chromogen which resulted in a brown-colored precipitate at the antigen sites of CD44 and CD133 (cytoplasmic stain). Slides were washed in PBS for five minutes then placed in 70\%, 95\% and 100\% alcohol for five minutes each. The nuclei were counterstained with Mayer's hematoxylin. Cover slips were mounted using Dpx. Positive and negative control slides for each marker were included within each session. As a negative control, liver tissue section was processed in the above-mentioned sequences but with omission of the primary antibodies.

\subsection{CD44 and CD133 Immunostaining Interpretation}

All immunostained slides were analyzed using Zeis microscope with high resolution (Axio Scope, Germany) in ten successive high-power fields (HPFs). Both CD44 and CD133 antigens were expressed as brown cytoplasmic staining. Two features of immuno-reactions were assessed separately on a semi-quantitative basis ( $\mathrm{H}$ score) as follows: 1) The extent of staining was assessed as the percentage of positively stained cells in 10 HPFs in the highest expression (hot spot) areas in each case. Then, means of percentages were calculated. 2) The intensity of staining of the positive cells was relatively designated as + (mild or weak), ++ (moderate), and +++ (strong) according to Itoi $\mathrm{H}$ et al., (28).

\subsection{Statistical analysis}

The data were analyzed using Microsoft Excel 2010 and Statistical Package for Social Science (SPSS version 22.0) for windows (SPSS IBM., Chicago, IL). Results were expressed as mean \pm SD with $95 \%$ confidence interval using mean for quantitative variables, frequencies and percentages for qualitative ones. $\mathrm{P}<0.05$ was considered statistically significant. Quantitative data were analyzed by applying one-way analysis of variance (ANOVA) test for comparison of the mean of more than two groups, while independent-samples t-test was used for comparison of the means of two groups. Chi-square test was used to compare proportions between two qualitative parameters.

\section{Results}

The study included seventy patients, of which, fifty (71.4\%) were males and twenty (28.6\%) were females. On serological evaluation, despite the progressive increase of total bilirubin and direct bilirubin with disease progression, the albumin significantly and steadily decreased with disease progression compared to control group $(p<0.05)$. Moreover, ALT and AST enzymes were above the upper normal limit in non cirrhotic cases, while the highest values were significantly recorded in the cirrhotic group compared to the control group ( $<<0.05$ ). Furthermore, gamma-glutamyl transpeptidase and alkaline phosphatase enzymes were higher in non cirrhotic cases than in the control group, with maximum levels reached in the HCC group $(\mathrm{p}<0.001)$. In addition, prothrombin concentration, white blood cells count, red blood corpuscle count, platelet count and hemoglobin levels showed significant progressive decrease with disease progression compared to the control group $(\mathrm{p}<0.05)$ (Table 1). On radiological evaluation, abdominal ultrasound screening of liver showed increased liver size in eight $(40 \%)$ cases of the non cirrhotic chronic hepatitis group, ten $(50 \%)$ cases of cirrhotic group and fifteen $(75 \%)$ cases of HCC $(\mathrm{p}<0.05)$ in comparison with the control group. Moreover, liver surface was smooth in all of the cases of the chronic hepatitis group, and it was irregular in all of the cirrhotic and HCC groups, with a statistically significant difference compared to normal $(\mathrm{p}<0.05)$. Furthermore, the liver texture in the non-cirrhotic group was bright in eight $(40 \%)$ cases, and coarse in twenty (100\%) cases of both cirrhotic and HCC groups (Table 2). On Histopathological evaluation, there was no tissue expression of CD44 and CD133 in the liver tissue of control normal group (Table 3). In contrast, group I (hepatitis non-cirrhotic) and group II (cirrhosis), CD44 and CD133 positive cells were predominantly visualized in the portal areas and/or within fibrous septa, while in group III (HCC) they were localized in peri-tumoral adjacent connective tissue and within invaded vessels, suggesting that these cells may undergo metastasis. Moreover, the mean expression of CD44 values showed a highly significant increase with disease progression as it raised from $33.7 \%$ in chronic non-cirrhotic hepatitis, to $58.65 \%$ in the cirrhotic group and up to $78.35 \%$ in HCC group ( $\mathrm{p}<0.05$ ). Similarly, the mean expression values of CD133 showed a significant increase with disease progression from $20.5 \%$ in the chronic non-cirrhotic hepatitis group, to $37.75 \%$ in the cirrhotic group, recording the highest value $(76.7 \%)$ in the HCC group $(\mathrm{p}<0.05)$ (Table 3, Figures 1,2$)$. 

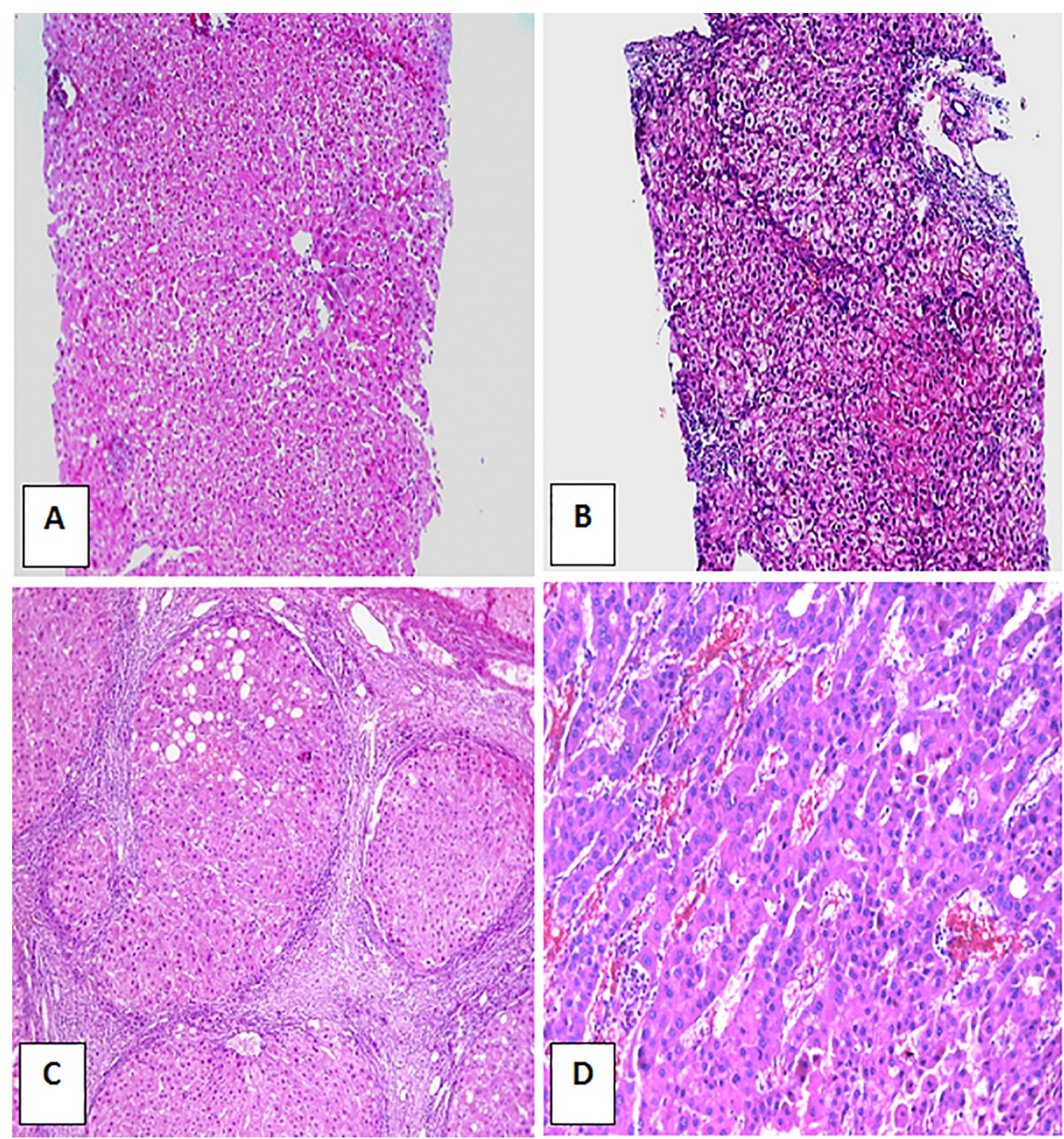

Figure 1. H\&E stained liver sections x100. A) Control non-infected normal liver. B) HCV-infected non-cirrhotic case showing A2 inflammatory activity and F1 fibrosis. C) HCV infected case showing F4 fibrosis with formation of cirrhotic nodule and A3 activity. D) HCC grade II (H\&E x200).

Table 1. Laboratory parameters of the studied groups (Mean \pm SD)

\begin{tabular}{|l|l|l|l|l|}
\hline Hepatic Profile & Control $(\mathrm{n}=10)$ & Group I $(\mathrm{n}=20)$ & Group II $(\mathrm{n}=20)$ & Group III $(\mathrm{n}=20)$ \\
\hline WBC & $6.02 \pm 1.3$ & $5.4 \pm 1.02$ & $(4.7 \pm 0.5)^{\mathrm{aa}, \mathrm{b}}$ & $(3.9 \pm 0.42)^{\mathrm{aa}, \mathrm{b}, \mathrm{c}}$ \\
\hline Hb & $13.8 \pm 0.27$ & $13.5 \pm 0.63$ & $(12.7 \pm 0.6)^{\mathrm{aa}, \mathrm{b}}$ & $(11.7 \pm 0.3)^{\mathrm{aa}, \mathrm{bb}, \mathrm{c}}$ \\
\hline PLTs & $210.3 \pm 48.5$ & $(182.4 \pm 27.5)^{\mathrm{a}}$ & $(122.1 \pm 29.05)^{\mathrm{aa}, \mathrm{bb}}$ & $(98.2 \pm 10.08)^{\mathrm{aa}, \mathrm{bb}, \mathrm{c}}$ \\
\hline ALT & $15.8 \pm 7.5$ & $(118.95 \pm 61.2)^{\mathrm{aa}}$ & $(81.5 \pm 31.8)^{\mathrm{aa}, \mathrm{b}}$ & $(97.9 \pm 25.8)^{\mathrm{aa}, \mathrm{b}, \mathrm{c}}$ \\
\hline AST & $17.2 \pm 8.5$ & $(108.2 \pm 48.4)^{\mathrm{aa}}$ & $(74.05 \pm 38.7)^{\mathrm{aa}, \mathrm{b}}$ & $(89.6 \pm 24.8)^{\mathrm{aa}, \mathrm{b}, \mathrm{c}}$ \\
\hline Alk.Ph & $98.6 \pm 9.07$ & $(164.2 \pm 25.2)^{\mathrm{aa}}$ & $(169.4 \pm 77.4)^{\mathrm{aa}}$ & $(256.8 \pm 72.6)^{\mathrm{aa}, \mathrm{bb}, \mathrm{cc}}$ \\
\hline GGT & $21.2 \pm 6.5$ & $(94.6 \pm 49.13)^{\mathrm{aa}}$ & $(101.4 \pm 68.8)^{\mathrm{aa}}$ & $(152.6 \pm 42.9)^{\mathrm{aa}, \mathrm{bb}, \mathrm{c}}$ \\
\hline Alb & $4.03 \pm 0.26$ & $(3.95 \pm 0.73)$ & $(3.46 \pm 0.49)^{\mathrm{aa}}$ & $(3.2 \pm 0.68)^{\mathrm{aa}, \mathrm{bb}}$ \\
\hline T. Bil & $0.72 \pm 0.18$ & $(1.4 \pm 0.65)^{\mathrm{aa}}$ & $(1.64 \pm 0.21)^{\mathrm{aa}}$ & $(2.8 \pm 1.08)^{\mathrm{aa}, \mathrm{b}, \mathrm{c}}$ \\
\hline D. Bil & $0.21 \pm 0.07$ & $(0.84 \pm 0.42)^{\mathrm{aa}}$ & $(1.18 \pm 0.32)^{\mathrm{aa}, \mathrm{b}}$ & $(1.89 \pm 1.18)^{\mathrm{aa}, \mathrm{b}, \mathrm{c}}$ \\
\hline PC & $93.2 \pm 4.9$ & $88.7 \pm 14.08$ & $(71.6 \pm 9.6)^{\mathrm{aa}, \mathrm{b}}$ & $(68.8 \pm 10.5)^{\mathrm{aa}, \mathrm{bb}}$ \\
\hline
\end{tabular}

${ }^{\mathrm{a}} \mathrm{p}=$ Another group compared with control; ${ }^{\mathrm{b}} \mathrm{p}=$ Group II and Group III compared with Group I; ${ }^{\mathrm{c}} \mathrm{p}=\mathrm{Group}$ III compared with Group II. 


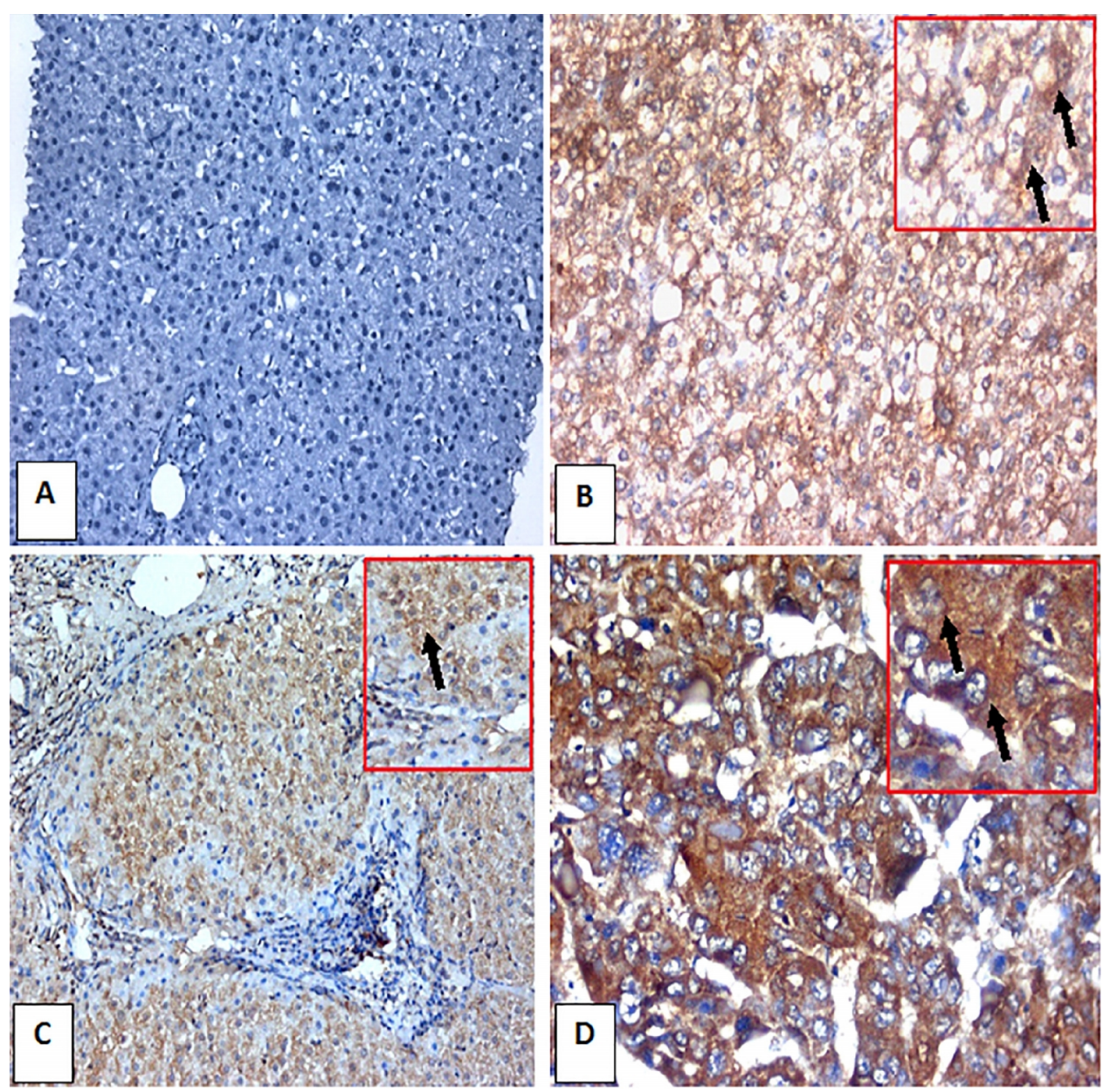

Figure 2. CD44 immunohistochemically stained liver sections. A) Control normal liver negative for CD44 (IHC, DAB. x200). B) HCV-infected non-cirrhotic case with A1 inflammatory activity, F1 fibrosis and 20\% expression of CD44 in hepatocytes as cytoplasmic brownish stain (arrow) (IHC, DAB. x200). C) HCV-infected case with A3 inflamatory activity and F4 fibrosis with formation of regenerating nodule and $>50 \%$ expression of CD44 in hepatocytes as cytoplasmic brownish stain (arrow) (IHC, DAB. x200). D) HCC grade II case with strong expression of CD44 in $>70 \%$ of hepatocytes as cytoplasmic brownish stain (arrows) (IHC, DAB. X400).

Table 2. Abdominal Ultrasound Features of the Studied Groups

\begin{tabular}{|c|c|c|c|c|c|c|c|c|c|c|}
\hline \multirow{2}{*}{\multicolumn{2}{|c|}{ Ultrasonography Findings }} & \multirow{2}{*}{\multicolumn{2}{|c|}{ Control $(n=10)$}} & \multirow{2}{*}{\multicolumn{2}{|c|}{ Group I $(n=20)$}} & \multirow{2}{*}{\multicolumn{2}{|c|}{ Group II $(n=20)$}} & \multicolumn{2}{|c|}{ Group III $(n=20)$} & p-value \\
\hline & & & & & & & & & & \\
\hline \multirow[t]{3}{*}{ Liver size } & Normal & 10 & 100.0 & 12 & 60.0 & 4 & 20.0 & 3 & 15.0 & \multirow{3}{*}{$0.01 *$} \\
\hline & Enlarged & 0 & 0.0 & 8 & 40.0 & 10 & 50.0 & 15 & 75.0 & \\
\hline & Shrunken & 0 & 0.0 & 0 & 0.0 & 6 & 30.0 & 2 & 10.0 & \\
\hline \multirow[t]{2}{*}{ Liver surface } & Smooth & 10 & 100.0 & 20 & 100.0 & 0 & 0.0 & 0 & 0.0 & \multirow[t]{2}{*}{$0.001 *$} \\
\hline & Irregular & 0 & 0.0 & 0 & 0.0 & 20 & 100.0 & 20 & 100.0 & \\
\hline \multirow[t]{3}{*}{ Liver Echo. } & Normal & 9 & 90.0 & 12 & 60.0 & 0 & 0.0 & 0 & 0.0 & \multirow[t]{3}{*}{$0.001 *$} \\
\hline & Bright & 1 & 10.0 & 8 & 40.0 & 0 & 0.0 & 0 & 0.0 & \\
\hline & Coarse & 0 & 0.0 & 0 & 0.0 & 20 & 100.0 & 20 & 100.0 & \\
\hline \multirow[t]{2}{*}{ PV dil } & Average & 10 & 100.0 & 20 & 100.0 & 3 & 15.0 & 1 & 5.0 & \multirow[t]{2}{*}{$0.01 *$} \\
\hline & Dilated & 0 & 0.0 & 0 & 0.0 & 17 & 85.0 & 19 & 95.0 & \\
\hline \multirow[t]{2}{*}{ Spleen } & Not Enlarged & 10 & 100.0 & 20 & 100.0 & 3 & 15.0 & 1 & 5.0 & \multirow[t]{2}{*}{$0.001 *$} \\
\hline & Enlarged & 0 & 0.0 & 0 & 0.0 & 17 & 85.0 & 19 & 95.0 & \\
\hline \multirow[t]{2}{*}{ Ascites } & Negative & 10 & 100.0 & 20 & 100.0 & 20 & 100.0 & 18 & 90.0 & \multirow[t]{2}{*}{$0.001^{*}$} \\
\hline & Positive & 0 & 0.0 & 0 & 0.0 & 0 & 0.0 & 2 & 10.0 & \\
\hline
\end{tabular}

*Significant differences between groups by ANOVA Test $(\mathrm{p}<0.05)$. 

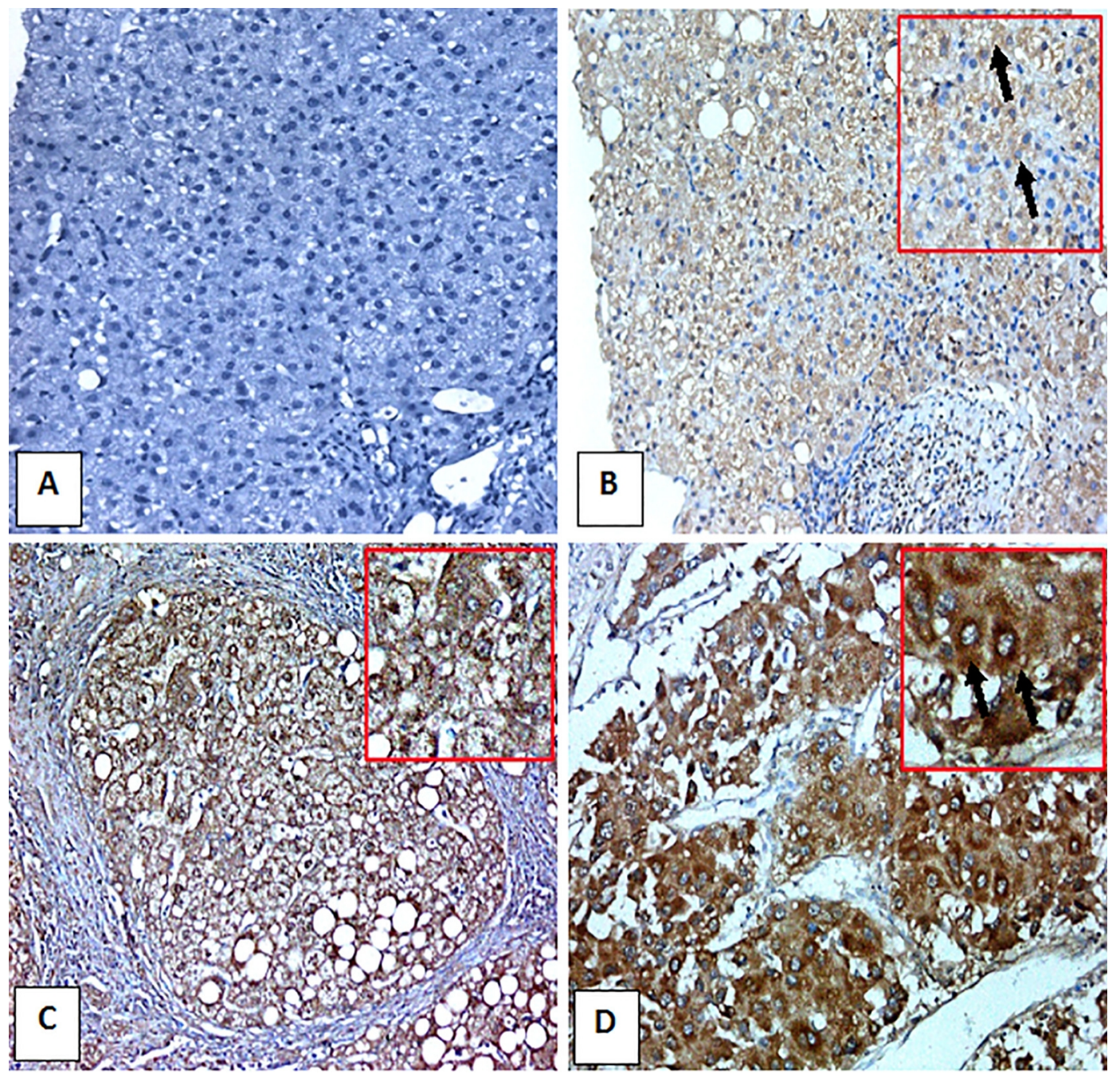

Figure 3. CD133 immunohistochemically stained liver sections. A) Control normal liver negative for CD133 (IHC, DAB. x200). B) HCV-infected non-cirrhotic case with A2 inflammatory activity, F1 fibrosis and 70\% expression of CD133 in hepatocytes as cytoplasmic brownish stain (arrow) (IHC, DAB. x200). C) HCV-infected case with A3 inflamatory activity, F4 fibrosis with formation of regenerating nodule and 50\% expression of CD133 in hepatocytes as cytoplasmic brownish stain (arrow) (IHC, DAB. x200). D) HCC grade II with 35\% expression of CD133 in hepatocytes as cytoplasmic brownish stain (arrows) (IHC, DAB. x200).

Table 3. Tissue expression of CD44 and CD133 among the studied groups

\begin{tabular}{|c|c|c|c|c|c|c|c|c|c|}
\hline \multirow[t]{2}{*}{ Biomarkers } & \multirow[t]{2}{*}{ Group } & \multirow[t]{2}{*}{$\mathrm{N}$} & \multicolumn{2}{|c|}{ Range } & \multirow[t]{2}{*}{ Mean } & \multirow[t]{2}{*}{ SD } & \multicolumn{3}{|l|}{$p$-value } \\
\hline & & & Min & $\operatorname{Max}$ & & & ${ }^{\mathrm{a} P}$ & ${ }^{b} \mathrm{P}$ & ${ }^{\mathrm{c}} \mathrm{P}$ \\
\hline \multirow[t]{4}{*}{$\mathrm{CD} 44$} & Control & 10 & 0.00 & 0.0 & 0.0 & 0.0 & & & \\
\hline & Group I & 20 & 5.00 & 75.0 & 33.7 & 25.4 & $0.001 *$ & & \\
\hline & Group II & 20 & 26.0 & 85.0 & 58.65 & 18.7 & $0.001 *$ & $0.001 *$ & \\
\hline & Group III & 20 & 50.0 & 97.0 & 78.35 & 13.63 & $0.001 *$ & $0.001 *$ & $0.001 *$ \\
\hline \multirow[t]{4}{*}{ CD 133} & Control & 10 & 0.0 & 0.0 & 0.0 & 0.0 & & & \\
\hline & Group I & 20 & 0.0 & 40.0 & 20.5 & 11.17 & $0.001 *$ & & \\
\hline & Group II & 20 & 20.0 & 60.0 & 37.75 & 12.4 & $0.001 *$ & $0.001 *$ & \\
\hline & Group III & 20 & 45.0 & 92.0 & 76.7 & 15.56 & $0.001 *$ & $0.001 *$ & $0.001 *$ \\
\hline
\end{tabular}

${ }^{a} \mathrm{p}=$ Another group compared with control; ${ }^{b} \mathrm{p}=$ Group II and Group III compared with Group I; ${ }^{\mathrm{c}} \mathrm{p}=$ Group III compared with Group II. *Significant differences between groups by ANOVA Test $(\mathrm{p}<0.05)$.

Furthermore, we found that the tissue expression of CD44 and CD133 raised with the increase of inflammatory activity and fibrosis stage evaluated with METAVIR score, with highly significant increase reported in A3F4 
(58.65\% for CD44 and 37.75\% for CD133 regarding A3 inflamatory activity score, and 58.65\% for CD44 and $37.75 \%$ for CD133 regarding F4 fibrosis stage / cirrhosis) compared to A1F1 (25.9\% for CD44 and 19.3\% for CD133 regarding A1 inflamatory activity score, and $21.4 \%$ for CD44 and $16.2 \%$ for CD133 regarding F0-F1 fibrosis stage) $(\mathrm{p}<0.05)$ (Tables 4, 5, Figure 3). Also in our study, there was a significant correlation with HCC grades with significant increase of CD44 and CD133 tissue expression among HCC grades (85.6\% for G3 compared to $72.1 \%$ for G1 regarding CD44 expression, and $77.3 \%$ for G3 compared to $74.2 \%$ for G1 regarding CD133 expression) $(\mathrm{p}<0.05)$ (Table 6). Nevertheless, there was no significant correlation between the expression of (CD44 and CD133) and the size of focal lesions (Table 6).

Table 4. The histopathological METAVIR scoring of the non-neoplastic groups

\begin{tabular}{|c|c|c|c|c|c|c|}
\hline \multirow{2}{*}{\multicolumn{2}{|c|}{ Classification }} & \multicolumn{2}{|c|}{ Group I (chronic non-cirrhotic hepatitis) } & \multicolumn{2}{|c|}{ Group II (cirrhosis) } & \multirow[t]{2}{*}{ p-value } \\
\hline & & $\mathrm{N}$ & $\%$ & $\mathrm{~N}$ & $\%$ & \\
\hline \multirow[t]{3}{*}{ Grades of inflammation } & A1 & 16 & 80.0 & 0 & 0.0 & \multirow[t]{3}{*}{$0.01 *$} \\
\hline & A2 & 4 & 20.0 & 0 & 0.0 & \\
\hline & A3 & 0 & 0.0 & 20 & 100.0 & \\
\hline \multirow[t]{3}{*}{ Stages of fibrosis } & F0-F1 & 11 & 55.0 & 0 & 0.0 & \multirow[t]{3}{*}{$0.01 *$} \\
\hline & F2-F3 & 9 & 45.0 & 0 & 0.0 & \\
\hline & F4 & 0 & 0.0 & 20 & 100 & \\
\hline
\end{tabular}

*Significant differences between groups by ANOVA Test $(\mathrm{p}<0.05)$.

Table 5. METAVIR inflamatory activity scores, fibrosis stages and tissue expression of CD44 \& CD133 among the non-neoplastic groups

\begin{tabular}{|c|c|c|c|c|c|c|c|c|}
\hline \multirow{3}{*}{\multicolumn{2}{|c|}{ Classification }} & \multirow[t]{3}{*}{$\mathrm{N}$} & \multicolumn{3}{|l|}{ CD44 } & \multicolumn{3}{|l|}{ CD133 } \\
\hline & & & \multirow[t]{2}{*}{ Mean \pm SD } & \multicolumn{2}{|l|}{$\mathrm{p}$-value } & \multirow[t]{2}{*}{ Mean \pm SD } & \multicolumn{2}{|l|}{ p-value } \\
\hline & & & & A1 & $\mathrm{A} 2$ & & A1 & $\mathrm{A} 2$ \\
\hline \multirow[t]{3}{*}{ Grades of inflammation } & A1 & 16 & $25.9 \pm 23.2$ & & & $19.3 \pm 9.5$ & & \\
\hline & $\mathrm{A} 2$ & 4 & $41.5 \pm 27.5$ & $0.001^{* *}$ & & $21.7 \pm 12.9$ & $0.03^{*}$ & \\
\hline & A3 & 20 & $58.65 \pm 18.7$ & $0.001^{* *}$ & $0.01^{*}$ & $37.75 \pm 12.4$ & $0.001^{* *}$ & $0.01^{*}$ \\
\hline \multirow[t]{3}{*}{ Stages of fibrosis } & F0-F1 & 11 & $21.4 \pm 23.3$ & & & $16.2 \pm 8.8$ & & \\
\hline & F2-F3 & 9 & $45.9 \pm 27.5$ & $0.001^{* *}$ & & $24.8 \pm 13.6$ & $0.01^{*}$ & \\
\hline & $\mathrm{F} 4$ & 20 & $58.65 \pm 18.7$ & $0.001^{* *}$ & $0.01^{*}$ & $37.75 \pm 12.4$ & $0.001^{* *}$ & $0.01^{*}$ \\
\hline
\end{tabular}

*Significant differences between groups by ANOVA Test $(\mathrm{p}<0.05)$.

Table 6. Tissue expression of CD44 and CD133 regarding HCC grades and size of the lesions

\begin{tabular}{|c|c|c|c|c|c|c|c|c|}
\hline \multirow[t]{3}{*}{ Classification } & & \multirow[t]{3}{*}{$\mathrm{n}$} & \multicolumn{3}{|l|}{ CD44 } & \multicolumn{3}{|l|}{ CD133 } \\
\hline & & & \multirow[t]{2}{*}{ Mean \pm S. D } & \multicolumn{2}{|l|}{ p-value } & \multirow[t]{2}{*}{ Mean \pm S. D } & \multicolumn{2}{|l|}{ p-value } \\
\hline & & & & Grade 1 & Grade 2 & & Grade 1 & Grade 2 \\
\hline \multirow[t]{3}{*}{ Grades of $\mathrm{HCC}$} & Grade 1 & 4 & $72.1 \pm 18.3$ & & & $74.2 \pm 10.9$ & & \\
\hline & Grade 2 & 8 & $77.3 \pm 10.9$ & 0.09 & & $76.3 \pm 15.6$ & 0.2 & \\
\hline & Grade 3 & 8 & $85.6 \pm 11.7$ & $0.01 *$ & $0.03 *$ & $79.5 \pm 19.2$ & $0.03 *$ & $0.05^{*}$ \\
\hline \multirow[t]{2}{*}{ Size of focal lesions $(\mathrm{cm})$} & $<5$ & 17 & $79.5 \pm 12.1$ & \multirow{2}{*}{\multicolumn{2}{|c|}{0.1}} & $76.5 \pm 16.08$ & \multirow{2}{*}{\multicolumn{2}{|c|}{0.2}} \\
\hline & $>5$ & 3 & $72.5 \pm 31.8$ & & & $84.5 \pm 13.4$ & & \\
\hline
\end{tabular}

*Significant differences between groups by ANOVA Test $(\mathrm{p}<0.05)$.

\section{Discussion}

Hepatitis C infection is a global health problem in which about 170 million individuals are infected annually worldwide (29). Egypt is one of the countries with the highest prevalence of HCV infection worldwide, predominantly with genotype-4, in over $90 \%$ of cases (30). Infection of HCV leads to chronic hepatitis in up to $60 \%-80 \%$ of patients and is associated with liver steatosis, fibrosis, cirrhosis, and hepatocellular carcinoma (31). HCC remains one of the most prevalent cancer types in past decades, despite great advances in anti-cancer drugs (32). Recently, much evidence has been accumulated supporting the hypothesis of CSCs subpopulation in solid tumors which indicates a capacity of self-renewal, tumor maintenance, metastasis (33) and resistance toward chemo and radio therapy (34). Therefore, it is significantly important to detect and investigate CSCs markers for determination of HCC clinical outcomes. In HCC, some of the most frequently reported CSCs markers are CD44 and CD133. In our study, histopathological examination of liver sections revealed absent tissue expression of CD44 in the normal liver control group. Moreover, the mean expression values of CD44 and CD133 level showed a 
statistically significant increase in cirrhotic livers (group II) and HCC (group III) compared to the non-cirrhotic group I, with a significant increase in group III compared to group II. Our findings were in agreement with Zhao et al. (35) who reported that in patients with liver cirrhosis, the number of patients with high CD44 expression was more than those with low CD44 expression, however in contrast, with non-significant differences. Also, our results coincided with Zhu et al. (36) who reported that CD44 was preferentially expressed in specific HCC cells (the CD133+ population) at both mRNA and the protein levels confirmed by real time RT-PCR and flow cytometric analysis. Moreover, our study showed no tissue expression of neither CD44 nor CD133 in the liver specimens of the normal control group. Our findings were in line with Ma et al., (37) study, in which CD133+ cells were found in human HCC tissue samples but not in normal liver tissues. Also, this came in agreement with Mansour et al., (38) who reported that CD133 expression was detected in HCCs as well as cirrhotic liver tissue but not in normal liver. In the same context, Zhao et al., (35) reported that liver cirrhosis significantly affected CD133 expression in which CD133 + cells were noticed in patients with liver cirrhosis rather than those without cirrhosis. In addition, we found that the tissue expression of both CD44 and CD133 increased and correlated significantly with METAVIR inflammation activity score and fibrosis stage, reaching the highest values in A3F4 cases compared to A1F1cases. Regarding HCC, we found significantly increased both CD44 and CD133 expression across all grades of HCC. Nevertheless, our study showed no significant correlation with the tumor stage. This came in agreement with Endo and Terada (39) who reported that CD44 expression was correlated with high HCC histologic grades, vascular invasion, and poorer survival outcomes. Also, similarly, Zhao et al. (35) reported that the size of HCC did not affect CD44 expression pattern. However, in contrast, recent meta-analysis data reported by Luo and Tan (40) indicated that CD44 expression correlated with HCC stage. Overall, our data imply that elevated CD44 and CD133 expression can contribute to HCC development and progression, and may be useful in identification of patients with poor HCC prognosis. Accordingly, CD44 and CD133 can function as prognostic markers for prediction of HCC outcomes. In this regard, Zhao et al. (35) observed shorter survival rates in HCCs exhibiting combined CD133 and CD44 expression. Moreover, positive CD44 expression was reported to be associated with a worse outcome and reduced survival compared to CD44-negative expression (40). Also, as previously mentioned, CD133 indicated poor HCC prognosis $(24,34)$, shorter overall survival and higher recurrence rate compared to patients with CD133- tumors $(41$, 42). Therefore, owing to the great heterogeneity of HCC, a combination of several markers can significantly increase the predictive power $(43,44)$, and help in the evolution of HCC therapeutic and preventive modalities.

\section{Conclusions}

Clusters of CD133+ and/or CD44+ CSCs were identified in chronic non-cirrhotic hepatitis, liver cirrhosis and HCCs, but not in normal liver. In non-neoplastic liver, their expression correlated with increased inflamatory activity and fibrosis stage. In HCCs, increased CD133 and CD44 expression corresponded to higher grade, thus indicating poorer prognosis. Therefore, the expression profiles of several CSCs markers can enhance our understanding of HCC initiation, progression, prognosis, metastasis and relapse, in addition to the help in the development of novel therapeutic agents targeting and/or preventing HCC.

\section{Acknowledgments:}

Authors acknowledge and thank the technicians in the pathology department, Theodor Bilharz Research Institute, for their efforts and help in slides preparation and handling.

\section{Conflict of Interest:}

There is no conflict of interest to be declared.

\section{Authors' contributions:}

All authors contributed to this project and article equally. All authors read and approved the final manuscript.

\section{References:}

1) Dai L, Ren $\mathrm{P}$, Liu M, Imai H, Tan EM, Zhang JY. Using immunomic approach to enhance tumorassociated autoantibody detection in diagnosis of hepatocellular carcinoma. Clin Immunol. 2014; 152(1-2): 127-39. doi: 10.1016/j.clim.2014.03.007. PMID: 24667685, PMCID: PMC4096568.

2) American Cancer Society. Cancer Facts and Figures. Atlanta, Ga: American Cancer Society; 2014.

3) El-Serag HB, Rudolph KL. Hepatocellular carcinoma: epidemiology and molecular carcinogenesis. Gastroenterology. 2007; 132(7): 2557-76. doi: 10.1053/j.gastro.2007.04.061. PMID: 17570226.

4) Ismail AM, Ziada HN, Sheashaa HA, Shehab El-Din. AB Decline of viral hepatitis prevalence among asymptomatic Egyptian blood donors: a glimmer of hope. Eur J Intern Med. 2009; 20(5): 490-3. doi: 10.1016/j.ejim.2009.03.005. PMID: 19712851. 
5) Gomaa AI, Hashim MS, Waked I. Comparing staging systems for predicting prognosis and survival in patients with hepatocellular carcinoma in Egypt. PLoS One. 2014; 9(3): e90929. doi: 10.1371/journal.pone.0090929. PMID: 24603710, PMCID: PMC3946382.

6) El-Serag HB. Epidemiology of hepatocellular carcinoma. Clin Liver Dis. 2001; 5(1): 87-107. doi: 10.1016/S1089-3261(05)70155-0.

7) Bruix J, Colombo M. Hepatocellular carcinoma: current state of the art in diagnosis and treatment. Best Pract Res Clin Gastroenterol. 2014; 28: 751. doi: 10.1016/j.bpg.2014.08.010. PMID: 25260305.

8) Nishi M, Sakai Y, Akutsu H, Nagashima Y, Quinn G, Masui S, et al. Induction of cells with cancer stem cell properties from nontumorigenic human mammary epithelial cells by defined reprogramming factors. Oncogene. 2014; 33(5): 643-52. doi: 10.1038/onc.2012.614. PMID: 23318426, PMCID: PMC4697746.

9) Xu XL, Xing BC, Han HB, Zhao W, Hu MH, Xu ZL, et al. The properties of tumor-initiating cells from a hepatocellular carcinoma patient's primary and recurrent tumor. Carcinogenesis. 2010; 31(2): 167-74. doi: 10.1093/carcin/bgp232. PMID: 19897602.

10) Sun JH, Luo Q, Liu LL, Song GB. Liver cancer stem cell markers: Progression and therapeutic implications. World J Gastroenterol. 2016; 22(13): 3547-57. doi: 10.3748/wjg.v22.i13.3547. PMID: 27053846, PMCID: PMC4814640.

11) Jaggupilli A, Elkord E. Significance of CD44 and CD24 as Cancer Stem Cell Markers: An Enduring Ambiguity. Clinical and Developmental Immunology. 2012; 2012. doi: 10.1155/2012/708036.

12) Naor D, Nedvetzki S, Golan I, Melnik L, Faitelson Y. CD44 in cancer. Crit Rev Clin Lab Sci. 2002; 39(6): 527-57. doi: 10.1080/10408360290795574. PMID: 12484499.

13) Al-Hajj M, Wicha MS, Benito-Hernandez A, Morrison SJ, Clarke MF. Prospective identification of tumorigenic breast cancer cells. Proc Natl Acad Sci U S A. 2003; 100(7): 3983-8. doi: 10.1073/pnas.0530291100. PMID: 12629218, PMCID: PMC153034.

14) Collins AT, Berry PA, Hyde C, Stower MJ, Maitland NJ. Prospective identification of tumorigenic prostate cancer stem cells. Cancer Res. 2005; 65(23): 10946-51. doi: 10.1158/0008-5472.CAN-05-2018. PMID: 16322242.

15) Dalerba P, Dylla SJ, Park IK, Liu R, Wang X, Cho RW, et al. Phenotypic characterization of human colorectal cancer stem cells. Proc Natl Acad Sci U S A. 2007; 104(24): 10158-63. doi: 10.1073/pnas.0703478104. PMID: 17548814, PMCID: PMC1891215.

16) Dan T, Hewitt SM, Ohri N, Ly D, Soule BP, Smith SL, et al. CD44 is prognostic for overall survival in the NCI randomized trial on breast conservation with 25 year follow-up. Breast Cancer Res Treat. 2014; 143(1): 11-8. doi: 10.1007/s10549-013-2758-9. PMID: 24276281.

17) Galizia G, Gemei M, Del Vecchio L, Zamboli A, Di Noto R, Mirabelli P, et al. Combined CD133/CD44 expression as a prognostic indicator of disease-free survival in patients with colorectal cancer. Arch Surg. 2012; 147(1): 18-24. doi: 10.1001/archsurg.2011.795. PMID: 22250106.

18) Tovuu LO, Imura S, Utsunomiya T, Morine Y, Ikemoto T, Arakawa Y, et al. Role of CD44 expression in non-tumor tissue on intrahepatic recurrence of hepatocellular carcinoma. Int J Clin Oncol. 2013; 18(4): 651-6. doi: 10.1007/s10147-012-0432-6. PMID: 22706704.

19) Sun J, Luo Q, Liu L, Zhang B, Shi Y, Ju Y, et al. Biomechanical profile of cancer stem-like cells derived from MHCC97H cell lines. J Biomech. 2016; 49(1): 45-52. doi: 10.1016/j.jbiomech.2015.11.007. PMID: 26627368.

20) Grosse-Gehling P, Fargeas CA, Dittfeld C, Garbe Y, Alison MR, Corbeil D, et al. CD133 as a biomarker for putative cancer stem cells in solid tumours: limitations, problems and challenges. J Pathol. 2013; 229(3): 355-78. doi: 10.1002/path.4086. PMID: 22899341.

21) Vander Griend DJ, Karthaus WL, Dalrymple S, Meeker A, DeMarzo AM, Isaacs JT. The role of CD133 in normal human prostate stem cells and malignant cancer-initiating cells. Cancer Res. 2008; 68(23): $9703-11$. doi: 10.1158/0008-5472.CAN-08-3084. PMID: 19047148, PMCID: PMC3072758.

22) Shmelkov SV, Butler JM, Hooper AT, Hormigo A, Kushner J, Milde T, et al. CD133 expression is not restricted to stem cells, and both CD133+ and CD133-metastatic colon cancer cells initiate tumors. J Clin Invest. 2008; 118(6): 2111-20. doi: 10.1172/JCI34401. PMID: 18497886, PMCID: PMC2391278.

23) Qin Q, Sun Y, Fei M, Zhang J, Jia Y, Gu M, et al. Expression of putative stem marker nestin and CD133 in advanced serous ovarian cancer. Neoplasma. 2012; 59(3): 310-5. doi: 10.4149/neo_2012_040. PMID: 22296500.

24) Suetsugu A, Nagaki M, Aoki H, Motohashi T, Kunisada T, Moriwaki H. Characterization of CD133+ hepatocellular carcinoma cells as cancer stem/progenitor cells. Biochem Biophys Res Commun. 2006; 351(4): 820-4. doi: 10.1016/j.bbrc.2006.10.128. PMID: 17097610. 
25) Liu H, Zhang W, Jia Y, Yu Q, Grau GE, Peng L, et al. Single-cell clones of liver cancer stem cells have the potential of differentiating into different types of tumor cells. Cell Death Dis; 2013; 4: e857. doi: 10.1038/cddis.2013.340. PMID: 24136221, PMCID: PMC3824650.

26) Bedossa P, Poynard T. An Algorithm for the Grading of Activity in Chronic Hepatitis C. The METAVIR Cooperative Study Group. Hepatology. 1996; 24(2): 289-93. doi: 10.1002/hep.510240201. PMID: 8690394.

27) Hsu SM, Raine L. Protein A, avidin, and biotin in immunohistochemistry. J Histochem Cytochem. 1981; 29(11): 1349-53. doi: 10.1177/29.11.6172466. PMID: 6172466.

28) Itoi H, Fujimori Y, Tsutsui H, Matsui K, Hada T, Kakishita E, et al. Differential upregulation of interleukin-18 receptor alpha chain between CD4+ and CD8+ T cells during acute graft-versus-host disease in mice. J Interferon Cytokine Res. 2004; 24(5): 291-6. doi: 10.1089/107999004323065075. PMID: 15153312.

29) Machlin ES, Sarnow P, Sagan SM. Masking the 5' terminal nucleotides of the hepatitis $C$ virus genome by an unconventional microRNA-target RNA complex. Proc Natl Acad Sci U S A. 2011; 108(8): 3193-8. doi: 10.1073/pnas.1012464108. PMID: 21220300, PMCID: PMC3044371.

30) Nguyen MH, Keeffe EB. Prevalence and treatment of hepatitis C virus genotypes 4, 5, and 6. Clin Gastroenterol Hepatol. 2005; 3(10 Suppl 2): S97-S101. doi: 10.1016/S1542-3565(05)00711-1. PMID: 16234071.

31) Bartenschlager R, Penin F, Lohmann V, André P. Assembly of infectious hepatitis C virus particles. Trends Microbiol. 2011; 19: 95-103. doi: 10.1016/j.tim.2010.11.005. PMID: 21146993.

32) Siegel R, Ma J, Zou Z, Jemal A. Cancer statistics, 2014. CA Cancer J Clin. 2014; 64(1): 9-29. doi: 10.3322/caac.21208. PMID: 24399786.

33) Malanchi I, Santamaria-Martínez A, Susanto E, Peng H, Lehr HA, Delaloye JF, et al. Interactions between cancer stem cells and their niche govern metastatic colonization. Nature. 2011; 481(7379): 85-9. doi: 10.1038/nature10694. PMID: 22158103.

34) Eyler CE, Rich JN. Survival of the fittest: cancer stem cells in therapeutic resistance and angiogenesis. J Clin Oncol. 2008; 26(17): 2839-45. doi: 10.1200/JCO.2007.15.1829. PMID: 18539962, PMCID: PMC2739000.

35) Zhao Q, Zhou H, Liu Q, Cao Y, Wang G, Hu A, et al. Prognostic value of the expression of cancer stem cell-related markers CD133 and CD44 in hepatocellular carcinoma: From patients to patient-derived tumor xenograft models. Oncotarget. 2016; 7(30): 47431-43. doi: 10.18632/oncotarget.10164. PMID: 27329727, PMCID: PMC5216952.

36) Zhu Z, Hao X, Yan M, Yao M, Ge C, Gu J, et al. Cancer stem/progenitor cells are highly enriched in CD133 (+) CD44 (+) population in hepatocellular carcinoma. Int J Cancer. 2010; 126(9): 2067-78. doi: 10.1002/ijc.24868. PMID: 19711346.

37) Ma S, Chan KW, Hu L, Lee TK, Wo JY, Ng IO, et al. Identification and characterization of tumorigenic liver cancer stem/progenitor cells. Gastroenterology. 2007; 132(7): 2542-56. doi: 10.1053/j.gastro.2007.04.025. PMID: 17570225 .

38) Mansour AH, Elkhodary TR, Anwar R, Habeeb MR, Mohammed MA. Regulation of cancer stem cell marker (CD133) by Transforming Growth Factor Beta in hepatocellular carcinoma. International Journal of Cancer research. 2014; 10(2): 65-73. doi: 10.3923/ijcr.2014.65.73.

39) Endo K, Terada T. Protein expression of CD44 (standard and variant isoforms) in hepatocellular carcinoma: relationships with tumor grade, clinicopathologic parameters, p53 expression, and patient survival. J Hepatol. 2000; 32(1): 78-84. doi: 10.1016/S0168-8278(00)80192-0. PMID: 10673070.

40) Luo Y, Tan Y. Prognostic value of CD44 expression in patients with hepatocellular carcinoma: meta-analysis. Cancer Cell Int. 2016; 16: 47. doi: 10.1186/s12935-016-0325-2. PMID: 27330410

41) Yoshikawa S, Zen Y, Fujii T, Sato Y, Ohta T, Aoyagi Y, et al. Characterization of CD133+ parenchymal cells in the liver: histology and culture. World J Gastroenterol. 2009; 15(39): 4896-906. doi: 10.3748/wjg.15.4896. PMID: 19842219, PMCID: PMC2764966.

42) Zeng Z, Ren J, O'Neil M, Zhao J, Bridges B, Cox J, et al. Impact of stem cell marker expression on recurrence of TACE-treated hepatocellular carcinoma post liver transplantation. BMC Cancer. 2012; 12: 584. doi: 10.1186/1471-2407-12-584. PMID: 23216644, PMCID: PMC3534240.

43) Sabet MN, Rakhshan A, Erfani E, Madjd Z. Co-Expression of Putative Cancer Stem Cell Markers, CD133 and Nestin, in Skin Tumors. Asian Pac J Cancer Prev. 2014; 15: 8161-9. PMID: 25339000.

44) Gandara DR, Lara PN Jr, Mack PC. Patient-Derived Xenografts for Investigation of Acquired Resistance in Oncogene-Driven Cancers: Building a Better Mousetrap. J Clin Oncol. 2015; 33(26): 2839-40. doi: 10.1200/JCO.2015.61.9692. PMID: 26215942. 